Motrivivência v.26, n.42, p. 207-221, junho/2014

\title{
A APRENDIZAGEM DO VOLEIBOL E A FORMAÇÃO DO CONCEITO SOBRE O JOGO
}

Made Júnior Miranda?

\section{RESUMO}

Esta pesquisa investigou os conhecimentos de voleibol desenvolvidos por 84 acadêmicos de educação física adquiridos em fases anteriores ao curso da disciplina Voleibol na graduação. O objetivo foi demonstrar as possíveis relações existentes entre o tipo das intervenções formativas e a expressão de conhecimentos teóricos científicos ou empíricos. Utilizou-se o método comparativo na explicação sociológica durkheimeana. Foi considerado como pensamento e conceitos empíricos as 84 respostas da questão sobre o conceito de voleibol. Concluiu-se que a aprendizagem dos estudantes foi demarcada pelo tratamento corriqueiro, empírico, imediato ou cotidiano dos objetos de aprendizagem, na acepção de Vigotski, Davídov, Libâneo e outros.

Palavras-chave: Formação de conceitos; Voleibol; Acadêmicos de Educação Física.

1 Doutor em Educação. Professor dos cursos de licenciatura em Educação Física da UEG/ESEFFEGO e PUC/ DEFD/GO. Goiás, Brasil.

E-mail: madejr@ig.com.br 


\section{INTRODUÇÃO}

Esta pesquisa fez uma investigação dos conhecimentos desenvolvidos pelos acadêmicos de educação física (EFI) adquiridos em fases anteriores ao curso da disciplina Fundamentos Metodológicos do Voleibol prevista na grade curricular do $5^{\circ}$ período da Escola Superior de Educação Física e Fisioterapia do Estado de Goiás (ESEFFEGO). A motivação para realizar este estudo veio da nossa experiência de ensino da disciplina Fundamentos Metodológicos do Voleibol nos cursos de graduação em Educação Física da ESEFFEGO e da Pontifícia Universidade Católica de Goiás (PUC), onde temos observado que os acadêmicos apresentam patamares de conhecimentos muito similares sobre a modalidade esportiva voleibol, caracterizado sobretudo por uma dificuldade de teorização do conhecimento organizado e sistematizado da modalidade enquanto um fenômeno esportivo, histórico e cultural. As diferenças mais comuns percebidas no trato dos acadêmicos com os elementos do voleibol são evidenciadas, em alguns casos, nos aspectos do domínio da motricidade que a prática solicita. Assim uma questão foi levantada: quais são as relações que podemos identificar entre o conceito escrito apresentado pelos acadêmicos a respeito do jogo de voleibol com as atividades que eles relataram terem vivenciado ao longo do processo de aprendizagem?

A hipótese formulada partiu da presunção de que os alunos que tiveram um nível mais propositivo de atividades de intervenções didático-pedagógicas na aprendizagem do voleibol durante as fases anteriores de escolarização apresentam uma formulação mais elaborada de conceitos relativos ao jogo de voleibol podendo compreender conceitos teóricos científicos e/ou empíricos conforme a relação entre o objeto trabalhado e o tipo de intervenção vivida. Neste contexto de investigação pretendeu-se com esta pesquisa contribuir para criar elementos significativos na análise do processo de ensino e aprendizagem, mais especificamente no campo da formação de professores para o ensino esportivo do voleibol.

\section{Objetivo geral}

Demonstrar as possíveis relações existentes entre o tipo das intervenções formativas anteriores e a expressão de conhecimentos teóricos científicos ou empíricos que os acadêmicos de EFI do quinto período matutino e vespertino da ESEFFEGO apresentam sobre a modalidade esportiva voleibol.

\section{Objetivos específicos}

a) Organizar os conhecimentos dos alunos em teóricos científicos ou empíricos em relação aos conteúdos do jogo de voleibol.

b) Fazer o levantamento e a organização das principais experiências sobre voleibol que os sujeitos da pesquisa tiveram na área do voleibol.

c) Fazer as possíveis correlações entre os objetivos específicos "a" e "b".

\section{REFERENCIAL TEÓRICO}

Diferentes estudos têm mostrado que os tipos de interferências que os alunos 
recebem durante o processo de formação vão refletir em diferentes domínios na vida egressa. Harrison et al. (2010) comparou dois modelos de ensino para acompanhar os efeitos de diferentes metodologias na aprendizagem de voleibol, Skill teaching e Mastery Learning-on Skill. Constatou-se que as estratégias de aprendizagem que aumentam o número total de contatos com a bola e o percentual de testes bem sucedidos em jogo, especialmente para os participantes menos qualificados deu efeitos favoráveis na aprendizagem. Cloes, Lapierre e Pieron (2005) desenvolveram uma pesquisa entre a metodologia de ensino de professoras especialistas e não-especialistas de voleibol. Consideraram como especialista as professoras com participação em campeonatos nacionais e cursos específicos de treinadores e como não-especialistas aquelas que tinham somente a formação básica. Os resultados mostraram que as tarefas desenvolvidas pelos especialistas estiveram mais em conformidade com as recomendações dos metodologistas. E sugerem diretrizes para os professores não especialistas; maior atenção a formação contínua; as formações devem ensinar como fazer e porque fazer. Assim, diante do papel fundamental das interferências educacionais e das atividades propositivas vamos abordar dois tópicos essenciais neste estudo: a mediação e a formação de conceitos.

\section{A mediação}

Aos seres humanos são atribuídas as capacidades mentais superiores que lhes permitem imaginar e planejar as atividades cotidianas. O fato de uma pessoa deixar de acender a luz porque verificou que há alguém dormindo no quarto, implica que na mente dela operou-se um processo mental intermediário que interferiu na sua resposta. O processo de intervenção de um elemento intermediário numa relação é chamado por Vygotsky (2007) de mediação. A mediação nos seres humanos, portanto, determina o "como", o "porque" e também se a atividade vai ser consumada, podendo ser qualquer intervenção humana individual ou de grupos, objetos ou situações que se interponha entre o estímulo e conduzindo a uma resposta. Para, além disso, os mediadores não apenas se interpõem ao estímulo e à ação, mas estão a todo o momento envolvido na nossa vida, permeando e influenciado nas respostas.

Podemos, então de acordo com Vygotsky (2007), dizer que o desenvolvimento humano acontece do meio externo do indivíduo para o meio interno dele (de fora para dentro), pois a formação do sistema simbólico dos signos depende, sobremaneira, da mediação social. Esta, por sua vez, estabelece os mediadores externos que serão operados na mente da pessoa para que a internalização ocorra no plano intra-mental. As ligações dos indivíduos com o mundo são ligações mediadas indiretamente pela atividade humana que transformam seu mundo material e sua consciência. Sendo que, a atividade do homem é pressuposto desta transformação e ao mesmo tempo o resultado dela.

\section{A formação de conceitos}

Vigotski (1996) investigou o processo de formação dos conceitos analisando as investigações dos colaboradores Ach \& Rimat, citados por ele. A partir da proposição de tarefas do tipo solução de problemas na 
ausência de conhecimentos ou experiência sobre o objeto em análise, ele quis saber que influência este contexto experimental tinha na formação do pensamento humano. Uma das conclusões postas foi de que as condições externas que não são propicias para a resolução dos problemas, apenas contribuem para uma mecanização entre o sujeito e o objeto. As condições externas devem favorecer a intervenção e a reflexão sobre o que está no ambiente para que seja possível a formação dos conceitos. Em outra situação investigativa, Vigotski verificou que a formação de conceitos faz parte de um processo criativo que surge no transcorrer das resoluções de problemas em operações complexas. Contudo, por si só, estas situações complexas não garantem a resolução de problemas, é preciso proporcioná-las aos alunos, como escreve Vigotski:

Se o meio ambiente não apresenta nenhuma dessas tarefas ao adolescente, não lhe faz novas exigências e não estimula seu intelecto, proporcionando-lhe uma série de novos objetos, o seu raciocínio não conseguirá atingir os estágios mais elevados, ou só os alcançará com grande atraso (VIGOTSKI, 1996, p.50).

Para Vigotski (1996) e seus colaboradores, os processos de formação dos conceitos se iniciam logo na infância, porém, a base psicológica (as funções intelectuais) para a formação de conceitos só se confirma na puberdade. Assim, a partir do pensamento conceitual amadurecido na adolescência ele dividiu o pensamento em três fases: a) A fase do pensamento sincrético - quando as crianças são capazes de agrupar, desorganizadamente, alguns objetos na tentativa de solucionar problemas que são postos. b) A fase dos pensamentos complexos - quando os objetos se associam na mente da criança de forma incompleta, dependendo de fatos concretos ou de experiências diretas. c) E a fase de formação dos conceitos propriamente ditos - quando se consegue abstrair e agrupar objetos sem base em nenhum atributo. No entanto, para Vigotski, os estágios não devem ser considerados em separado, mas no processo de formação de conceitos do indivíduo.

A formação de conceitos se processa diferentemente em crianças, adolescentes e adultos. Por exemplo, a palavra bola pode ser na mente da criança um elemento bastante diferente do que na mente de um adulto, mesmo que ambos utilizem o mesmo termo para se referirem a esse objeto. Vigotski enfatiza que o elemento bola será a mesma coisa para adultos e crianças quando for utilizada por estes grupos de forma igual. Deste ponto, podemos imaginar o quanto o contexto de educação é importante na formação da criança, incluindo-se aí a didática, as condições externas, os programas de estudos, os currículos, a competência dos professores etc.

A idéia que Vigotski (1996) coloca sobre a formação de conceitos é que o processo de aprendizagem não se encerra quando se aprende algo, pois há uma dinâmica durante a aprendizagem em que os próprios processos mentais são direcionados com a ajuda das palavras ou signos.

Os conceitos se formam e se desenvolvem interna e externamente, dependendo da forma que foram originados. Assim, há dois tipos de conceitos que a mente humana pode processar, os conceitos empíricos (do cotidiano) e os conceitos científicos. Exemplificando, quando um adolescente executa um saque no jogo de voleibol, ele provavelmente dirá que foi um ato consciente no decorrer da partida, mas, caso ele 
não saiba explicar cientificamente "como" o fez, isto quer dizer que seus movimentos para o saque ainda não são movimentos conscientemente concebidos. Neste caso, o adolescente só terá consciência na ação de sacar quando o "como", "o modo de" sacar for objeto da sua consciência. Assim, um novo jeito de ver as coisas, se dá a partir da conscientização sobre elas, permitindo que elas sejam pensadas também por outros pontos de vista. À medida que aumenta consciência sobre o saque, aumenta também a possibilidade de compreendê-lo dentro do jogo de voleibol. Ou seja, fica claro que vários conceitos, um sistema de conceitos sistematizados, só pode aumentar o grau de consciência de uma pessoa. Em relação aos conceitos científicos Vygotsky considera aqueles que precisam ser sistematizados (investigado, comprovados) para serem ensinados. Ele escreve:

Portanto, um conceito é algo que resume, generaliza as características de cada objeto, palavra ou situação. Aprender a direcionar os próprios processos mentais com a ajuda das palavras ou quando transmitimos à criança um conhecimento sistemático, ensinamos-lhe muitas coisas que ela não pode ver ou vivenciar diretamente. Uma vez que os conhecimentos científicos e espontâneos diferem quanto a sua relação com a experiência da criança, e quanto à atitude da criança para com os objetos, pode-se esperar que o seu desenvolvimento siga caminhos diferentes desde seu início até a forma final (VYGOTSKI, 1996, p.74).

A partir da investigação de conceito, Vygotsky constatou que um conceito indica uma generalização, que por sua vez, implica e depende de outros conceitos ordenados. Exemplifica o autor:
[...] uma criança aprende a palavra flor, e logo depois a palavra rosa: durante muito tempo, o conceito de "flor", embora de aplicação mais ampla do que "rosa", não pode ser considerado o mais geral para a criança. Não inclui e nem subordina a si a palavra "rosa" - os dois são intercambiáveis e justapostos. Quando "flor" e "rosa", assim como entre "flor" e outros conceitos subordinados também se modifica na mente da criança. Um sistema está se formando (VIGOTSKI, 1996, p.80).

A formação de conceitos científicos, além de depender de um sistema de conceitos, também é fundamental para modificar os conceitos do cotidiano. Isto confere importantes incumbências a quem ensina, cabendo-Ihes a devida apropriação dos conhecimentos históricos e científicos já acumulados pela humanidade. Destaca-se, contudo, que devido a dinâmica imposta ao processo de generalização para a formação dos conceitos, há de ter-se a atenção para as constantes modificações e criação de novos conceitos. A atualização sobre os objetos de estudo deve ser permanente, porque a todo o momento novas generalizações estão convertendo conhecimentos do cotidiano em científicos e vice-versa.

De fato, o que Vygotsky propôs investigar foi o processo complexo de abstração, generalização e formação de conceitos desenvolvidos pela consciência humana durante a atividade de aprendizagem. Leontiev (1992) trouxe sua contribuição ao analisar a estrutura da atividade psicológica humana mediante suas necessidades, motivos e objetos.

Para Libâneo (2004) o conceito na teoria histórico-cultural não se restringe às características e propriedades dos fenômenos em análise, pois há uma ação mental própria do sujeito pela qual se realiza uma 
reflexão sobre um objeto para captar o conceito nuclear do fenômeno estudado que é, ao mesmo tempo, um meio de reconstrução mental desses objetos pelo pensamento. Desta forma, o pensamento teórico é uma atividade mental que, com base em uma relação geral, um princípio geral, possibilita ao indivíduo resolver problemas específicos, pela possibilidade de generalização dos conceitos já formados.

Um critério para o conceito autenticamente científico ou teórico é, segundo nós, aquele seu conteúdo que, mediante certas ações intelectivas, particularmente a reflexão, fixa certas relações genéticas fixas de pertencimento ou a "célula" de um determinado sistema de objetos em desenvolvimento. Sobre a base desta célula, pode-se deduzir mentalmente por este conceito o processo total do desenvolvimento do sistema dado. Em outras palavras, o pensamento e os conceitos empíricos consideram os objetos como constantes e acabados, enquanto que o pensamento e os conceitos teóricos analisam os processos do seu desenvolvimento (DAVÍDOV, 1992, p.7).

Ou seja, para o autor, a atividade de ensino que se baseia na generalização teórica a partir dos conceitos científicos, deve analisar autonomamente os dados da tarefa, separando neles as conexões essenciais e considerando particularmente cada tarefa como uma variação própria daquela tarefa que já havia sido resolvida inicialmente por meios teóricos. Em síntese, a formação de conceitos é um processo pelo caminho da elevação do abstrato para o pensamento concreto. Este processo se inicia na atividade de identificação da relação geral com o conteúdo em análise Ao captar as regularidades entre os objetos já estudados e o objeto em estudo (abstração ${ }^{2}$ substantiva) a pessoa terá condições (em sua mente) para estabelecer os vínculos e fazer uma generalização substantiva.

Como salienta Libâneo (2004), os conteúdos (matérias de ensino) para serem aprendidos devem ser organizados de tal forma que propiciem e facilitem a formação de conceitos e a generalização por parte de quem aprende. É necessário, portanto, um planejamento de ensino que favoreça este processo para a obtenção de resultados com eficácia.

\section{METODOLOGIA}

Método de pesquisa:

Foi utilizado o método comparativo para organizar e analisar os grupos de respostas conforme as suas caracterizações. Assim adotamos o método comparativo na explicação sociológica durkheimeana.

A sociologia, segundo Durkheim (1985), deve seguir o caminho da experimentação indireta ou a análise das variações concomitantes, fazendo uso, portanto, de um procedimento indutivo, e não dedutivo, como propunha Comte (1988). Pela variação concomitante, ou pelo simples paralelismo de uma variável, pode-se verificar se a causa é permanente e, neste

2 Abstração - um conceito no qual não se leva em conta um valor específico determinado e sim qualquer entre todos os valores possíveis daquilo com que estamos lidando ou ao que estamos nos referindo. Ou seja, podemos entendê-la como uma análise redutora e simplificadora do complexo mundo senso - perceptivo em que vivemos, fundamentando o pensamento que nos permite tomar as decisões adequadas, visando garantir nossa sobrevivência como indivíduos e como espécie (CUVILIER, 1950). 
caso, verificar se há uma lei de explicação. A concomitância é a prova de que uma causa existe em dois fenômenos sociais e que, portanto, tende a produzir os mesmos efeitos e ter funções semelhantes.

Durkheim estava ciente de que por mais competente que pudesse ser o investigador, ele dificilmente poderia garantir certeza total na análise dos efeitos ou dos antecedentes históricos (conhecidos ou não) responsáveis por uma determinada causa. A comparação ganha, aqui, um papel de destaque em sua proposta teórico-metodológica. Para Durkheim o pesquisador durante a utilização do método comparativo deve:

[...] comparar, não variações isoladas, mas séries de variações regularmente constituídas e, o que é mais, suficientemente extensas, cujos termos se liguem uns aos outros por uma gradação tão contínua quanto possível. Pois as variações de um fenômeno não permitem chegar a uma lei, a não ser que exprimam claramente a maneira pela qual ele se desenvolve em circunstâncias dadas [...] (DURKHEIM, 1985, p. 118).

Assim fizemos uma pesquisa de campo buscando explorar e explicar os fatos observados (CRESWELL, 2007). A pesquisa foi desenvolvida dentro da UEG/ESEFFEGO junto aos acadêmicos do $5^{\circ}$ período do curso de graduação em EFI. Participaram da pesquisa 84 acadêmicos matriculados na disciplina Fundamentos Metodológicos do Voleibol no ano de 2013.

\section{PROCEDIMENTOS PARA COLETA DE DADOS}

Os acadêmicos participantes da pesquisa responderam ao questionário logo no início do semestre letivo, no primeiro e segundo semestres de 2013 respectivamente. O questionário foi aplicado em sala de aula, logo no primeiro momento e encontro com o professor (pesquisador), antes de qualquer comunicação sobre a ementa e conteúdos da disciplina. Os questionários foram respondidos individualmente e não foi permitida a consulta de materiais ou o auxílio de outras pessoas nas respostas, sob pena de exclusão da pesquisa. A identidade dos sujeitos participantes na pesquisa foi omitida nesse estudo. Foram excluídos os alunos repetentes e aqueles que já tinham iniciado a disciplina voleibol em semestres anteriores.

\section{ANÁLISE DE DADOS}

A análise dos dados procurou ordenar, estruturar e atribuir significados, transformando os dados coletados em conclusões e/ou lições úteis para o campo educacional em investigação. Buscamos identificar tendências, variações e diferenças nos dados obtidos.

Nos aspectos qualitativos procurou-se indagar porque determinado fato ou problema está ocorrendo. Nos aspectos quantitativos reunimos os dados que capazes de produzir informações sobre a magnitude dos problemas observados. A categorização em pensamento teórico ou empírico considerou a aproximação das respostas com o referencial teórico apresentado.

\section{RESULTADOS E DISCUSSÃO}

Conforme está colocado no questionário do Apêndice 1, para a resposta da questão "Conceitue a modalidade esportiva Voleibol" foi proposta a leitura de um referencial teórico no sentido de apresentar 
para o entrevistado a orientação do pesquisador sobre o conceito de conceito. Assim procedemos a leitura de todas as respostas manuscritas pelos entrevistados e buscamos a observação das variações concomitantes conforme a proposta de Durkheim (1985). A análise das respostas foi feita considerando-se, sobremaneira, a subjetividade, mas grosso modo buscando organizar as respostas de tal forma que o teor dos conceitos fosse colocado em alguns grupos com características semelhantes ou conforme disse Durkheim (1985) em séries de variações regularmente constituídas. Ou seja, tendo a relativa atenção para que o conceito emitido pelo entrevistado não fosse colocado em um contexto que não caracterizasse a sua essência. Neste sentido as respostas do conceito dos acadêmicos sobre a modalidade esportiva voleibol foram organizadas em dois grupos e subgrupos, sendo:

a) Pensamento e conceitos empíricos. Caracterizamos neste grupo as respostas cuja teorização que o participante fez exprimiu, especialmente, o pensamento de fatores contextuais do voleibol como os aspectos da coletividade; das regras; do desempenho; dados descritivos; mecanismo e formato do jogo; mas, não atingiu a perspectiva sistematizada do percurso histórico, social e cultural que abrange a produção científica do voleibol enquanto um esporte. Podemos dizer que se trata de um senso comum sobre o voleibol que obviamente foi influenciado por sucessivas vivencias mas, aqui, não percebidas como cientificamente tratadas nas suas fundamentações. Como disse Hedgaard (2011, p. 201) "os conceitos corriqueiros são desenvolvidos espontaneamente numa relação dialética com os conceitos científicos, que são mediados pelo ensino.
Os conceitos interpretados como sendo de pensamentos e conceitos empíricos foram subdivididos em:

a.1) Pensamento e conceito empírico com aspectos descritivos do objeto de análise. Foram os conceitos considerados mais elaborados na sua construção. Ou seja, mesmo não caracterizando um conceito na acepção científica apresentada neste esudo, observamos que o participante da pesquisa conseguiu fazer um maior destrinçamento de conteúdos pertinentes ao contexto da questão formulada.

a.2) Pensamento e conceito empírico extremamente reducionista do objeto de análise. Foram consideradas as respostas cujo participante da pesquisa restringiu bastante a descrição do objeto de estudo e não conseguiu expressar-se analiticamente e nem com alguma riqueza descritiva sobre a questão proposta, simplificando ao máximo a sua resposta.

b) Pensamento e conceitos científicos. Consideramos as respostas que conforme a interpretação do pesquisador conseguiram retratar no conceito escrito uma ideia de voleibol dentro de um movimento de desenvolvimento da modalidade que minimamente incluiu sua condição no tempo histórico, sua localização nos espaços de intervenção, sua abrangência nas dimensões da vida humana e indo além do sensorial e perceptivo, sobretudo, com fundamentação na análise do percurso investigativo que originou o conhecimento histórico, social e cultural até então produzido e sistematizado pela humanidade no referido objeto de estudo. Conforme Ferreira (2011, p.17) esse tipo de pensamento "busca a essência das coisas nas suas contradições constitutivas e nas relações entre fenômenos por meio dessa essência 
e não por meio de características superficiais, como no pensamento empírico". Para avaliar a pertinência e a fundamentação dos conteúdos mais técnicos dos textos elaborados pelos entrevistados utilizamos como base o referencial bibliográfico da disciplina Fundamentos Metodológicos do Voleibol da ESEFFEGO, entre eles Bizzocchi (2000), Bojikian (2005), Borsari(1989), Carvalho (1982), CBV (2013), Coletivo de Autores (1992), Darido \& Rangel (2005), Kunz (2000), Caparroz (2001), Soler (2005) e Marchi Júnior (2004).

Portanto, a análise da questão "Conceitue a modalidade esportiva Voleibol" obteve 84 respostas, onde em média os acadêmicos precisaram oito linhas e meia $(8,5)$ para responderem. Conforme estabelecemos como elementos caracterizadores de um conceito científico, consideramos como pensamento e conceitos empíricos todas as 84 respostas da questão sobre o conceito da modalidade esportiva voleibol. Sendo que, trinta e oito (38) respostas foram consideradas como sendo caracteristicamente de pensamentos e conceitos empíricos com aspectos descritivos do objeto de análise e quarenta e seis (46) como sendo de pensamentos e conceitos empíricos extremamente reducionistas do objeto de análise. Algumas respostas escolhidas ao acaso foram transcritas logo abaixo. As respostas $a, b$ e $c$ representam respectivamente os conceitos com aspectos descritivos e as respostas $d$, e e $f$ os conceitos reducionistas do objeto de análise:

a) "O voleibol é uma modalidade de esporte coletivo em que são utilizadas as mãos para o manuseio da bola. É caracterizado pela presença de duas equipes formadas por seis jogadores titulares cada. O espaço de jogo é dividido ao meio por uma rede que tem sua altura variável de acordo com categorias e com o gênero. Antigamente a pontuação obedecia a lei da vantagem e, hoje em dia, segue de acordo com os sets cada um de 25 pontos, sendo que um ponto é marcado quando toca o solo, ou a antena (ou a fita que acompanha a antena), ou quando a equipe efetua mais de 3 toques na bola".

b) "O voleibol é uma modalidade esportiva coletiva, ou seja, é um jogo composto por duas equipes, com seis integrantes de cada lado. A quadra possui suas dimensões oficiais e ao meio há uma rede, na qual as equipes devem manejar a bola com as mãos e arremessá-la ao outro lado da rede faz ponto a equipe que mais acertar o outro lado da quadra, ou seja, a bola deverá cair na quadra adversária. No jogo existem ataques, defesas, saques, dentre outros. É um esporte que deve ter táticas e ocorrer trabalhos em grupo, é um jogo que há uma integração de todos os participantes".

c) "O voleibol é um esporte. Esporte esse que podemos classificar dentro dos esportes de rendimento, onde os atletas treinam e aperfeiçoam o físico e as técnicas em busca de resultados. O voleibol é um esporte popularmente conhecido, com grandes ligas por todo o mundo, tanto é que é considerado e faz parte dos olímpicos. Não só constitui-se do rendimento, também 'jogado e praticado como lazer, com regras modificadas para facilitar 
para aqueles com menos técnica. No vôlei usa-se as mãos para tocar a bola, mas não só as mãos, outras (todas) partes do corpo também são permitidas a tocar a bola. É disputado com seis atletas de cada lado na modalidade in door, e na de praia com dois atletas de cada lado".

d) "Modalidade esportiva, predominância do uso das mãos em que o objetivo é conseguir com que a bola encoste ou toque no chão do adversário, marcando o ponto".

e) "É um esporte regido por regras firmadas no plano imaginário, sendo respeitadas no espaço de tempo que ocorre a partida".

f) "Modalidade esportiva, que engloba trabalho em equipe, coordenação e habilidade motora, agilidade e resistência física".

Conforme disse Libâneo (2009) "Um conceito não é sinônimo de definição". Ou seja, para esse autor um conceito não são aquelas informações que temos na cabeça; não é acumulação de conteúdos. O conceito científico extrapola o contexto perceptual imediato (papel da definição). O conceito é um instrumento simbólico, uma ferramenta do pensamento, instrumentos do nosso pensamento, uma faculdade do nosso pensamento para fazer mediação cognitiva em relação ao conhecimento das coisas. Quem pensa, pensa porque é capaz de formular conceitos. Uma coisa é saber as características, as semelhanças e diferenças sobre o sol. Outra é ter consciência do conceito de "sol": fonte de luz e calor, ligação com a vida na terra, papel no sistema solar, relação com outros astros. Porque devemos ter cuidado com a luz do sol?
De forma geral quando os participantes da pesquisa se propuseram a formular um conceito de voleibol percebemos que eles ficaram muito restritos as regras e ao modo de jogar o voleibol, sobretudo com uma visão de esporte olímpico. Em geral os entrevistados expressaram pouca ou nenhuma valorização dos sujeitos que jogam, já jogaram ou que podem vir a jogar voleibol bem como suas particularidades e contextos de prática que podem desvincular totalmente o jogo da pespectiva tradicional e pragmática da qual os esportes estão estabelecidos na sociedade.

A segunda questão proposta para os entrevistados quis saber sobre as experiências que eles tiveram com o jogo de voleibol. Assim procedemos a análise das respostas separadas pelos dois grupos caracterizados na questão anterior. Ou seja, o grupo com respostas interpretadas pelo pesquisador como sendo de pensamento e conceito empírico com aspectos descritivos do objeto de análise e o grupo de pensamento e conceito empírico extremamente reducionista do objeto de análise. Basicamente os participantes responderam as seguintes questões: a. Como foi a sua aprendizagem do jogo de voleibol em espaços formais e informais (escolas, clubes etc.)?; b. Fale sobre a formação e o papel desempenhado por seus professores no ensino de voleibol; c. Quais foram os conteúdos que você trabalhou nas aulas de voleibol?; d. Descreva as condições de instalações, materiais e metodologias percebidas por você durante o processo de ensino-aprendizagem do voleibol; e. Fale sobre a freqüência anual, mensal e semanal das aulas de voleibol. Tempo de prática, torneios, campeonatos; f. Para além da prática do jogo de voleibol você já assistiu, acompanhou, fez pesquisas, 
cursos, adquiriu materiais didáticos-pedagógicos, enfim, teve experiências extras com a modalidade voleibol?

Sobre as questões supracitadas verificamos que a grande maioria dos participantes tiveram como referencia de aprendizagem de voleibol a escola onde fizeram o ensino fundamental e médio. Somente dois entrevistados relataram experiências de treinamentos em clubes com foco específicos em eventos competitivos a nível regional. Assim, não foi possível estabelecer uma relação direta considerável entre o grupo que consideramos ter expressado um pensamento e conceito empírico com aspectos descritivos e o grupo de pensamento e conceito empírico extremamente reducionista do objeto de análise. Haja vista que, excetuando os dois entrevistados que tiveram experiências de treinamentos em clubes, os demais caracterizaram as intervenções que tiveram no período escolar de forma muito similar.

De forma geral constatamos que o voleibol foi desenvolvido nas escolas, tanto públicas quanto privadas, na base de rodizios com outras modalidades, sendo que o futebol/futsal ocupava a maior parte do tempo das atividades esportivas da EFI. O processo ou metodologia de ensino não foi visto como sistematizado ou especializado, ficando os conteúdos restritos ao ensino das regras do jogo e das técnicas básicas. Muitos consideraram que as atividades das aulas ficavam em torno dos "três cortes" ou Ihes eram entregues uma bola para jogarem livremente na escola. A maioria considera que apesar de ter praticado na escola a aprendizagem foi informal com aulas eminentemente práticas, sem detalhamento dos gestos técnicos e sem as discussões sobre os conteúdos de trabalho, sobretudo aulas na forma de lazer/lúdico. Respondeu um entrevistado: "Foi um aprendizado de certa fora seco, não aprendi muitas regras, sinais, etc; aprendizagem mais do básico do voleibol mesmo. Na escola". Uma parcela menor de alunos considera que nunca teve aprendizado na escola e nem em outro espaço. Uma parte dos acadêmicos relataram ter tido boas condiçoes de materias e de instalaçoes e outra parte equivalente diz ter vivenciado a precariedade do meios disponíveis da escola. Também ficou claro na análise das respostas a influência dos eventos televisionados na formação do pensamento e conceito dos alunos sobre o voleibol, em especial da Super Liga Nacional, Liga Mundial, Mundial e Olmpíadas. Eles relataram que boa parte do que sabem sobre voleibol vem da posição de expectadores dos eventos esportivos.

Podemos depreender até aqui que o trabalho com os conteúdos do voleibol no âmbito escolar não refletiu na expressão escrita aspectos eminentemento de atividades organizadas capazes de elevar o nível de discussão teórica, tomando-se como base o conhecimento teórico e científico produzido pela humanidade até o momento. Como disse LiBâneo:

[...] devemos entender o processo de ensino como o conjuno de atividades organizadas do professor e dos alunos, visando alcançar determinados resultados (domínio e conhecimentos e desenvolvimento das capacidades cognitivas), tendo como ponto de partida o nível atual de conhecimentos, experiências e de desenvolvimento mental dos alunos (LIBÂNEO, 1990, p.79)

Duas pergundas de carácter objetivo foram feitas aos participantes da pesquisa: a) Cite os nomes fundamentos técnicos do jogo de voleibol, ou seja, os nomes dos 
gestos que foram sendo sistematizados durante o desenvolvimento histórico da modalidade; b) Quais são as dimensões oficiais (CBV, 2013) da área de jogo interna (quadra de voleibol)?

Consideramos como resposta satisfatoria para a questão "a)" aqueles que fizeram referência a pelo menos quatro fundamentos básicos dos jogo (BIZZOCCHI, 2000), ou usaram termos similares. Dentre eles: Saque, toque/levantamento, ataque/cortada, bloqueio, manchete/defesa. Para a questão "b)" consideramos 9 metros de largura por 18 de comprimento (CBV, 2013).

As frequências das respostas e seus percentuais foram organizados considerando os participantes da pesquisa dispostos nos dois subgrupos. Sendo, aqueles que manifestaram um conceito do jogo de voleibol aqui entendido como de conhecimento empírico descritivo e o outro subgrupo entendido como de conhecimento emprírico reducionsta do conceito do objeto voleibol.

Tabela 1: Conhecimento sobre os fundamentos e dimensões da quadra de voleibol

\begin{tabular}{lcccc}
\hline & \multicolumn{2}{c}{ Conhecimento empírico descritivo f(\%) } & \multicolumn{2}{c}{ Conhecimento empírico reduconista f(\%) } \\
\cline { 2 - 5 } & Satisfatória & Não satisfatória & Satisfatória & Não satisfatória \\
\hline Fundamentos & $27(71.0)$ & $11(29.0)$ & $42(91.3)$ & $4(8.7)$ \\
Dimensões & $10(26.3)$ & $28(73.6)$ & $4(8.7)$ & $42(91,3)$ \\
\hline
\end{tabular}

Observamos na Tabela 1 que a maior parte dos alunos (69 ou $81 \%$ ) conhece pelos menos quatro fundamentos básicos do jogo de voleibol e que a grande maioria (72 ou $83 \%$ ) não sabe as dimensões da quadra de jogo. Os dados evidenciaram que os alunos categorizados como com conhecimento e conceito teórico empírico extremamente reducionista na análise do conceito sobre o jogo de voleibol conhece mais fundamentos do jogo (42 ou $91.3 \%$ ) e menos sobre as dimensões da quadra de voleibol (4 ou 8.7\%) quando comparados com os alunos que foram considerados com conhecimento e conceito teórico empírico descritivo na análise do conceito sobre o jogo de voleibol. A análise nos mostra que o tipo de conhecimentos manifestado pelos alunos nas respostas dos questionários é compatível com as experiências que eles relataram ter tido no processo de ensino e aprendizagem do voleibol. Uma vez que o contato deles foi basicamente através da prática elementar e assistemática com o voleibol, seja na escola, no lazer fora da escola e como expectadores da televisão, isto justifica uma dificuldade na compreensão e elaboração de conceitos científicos sobre os objetos. Como disse Vigotski (1996) é preciso que o meio ambiente, aqui entendido como as escolas, ofereça aos alunos as atividades propositivas capazes de elevar o seu nível de raciocínio no desenvolvimento da tarefa em situação compatível com os estágios de desenvolvimento do conhecimento sobre o objeto investigado.

Outro dado que ficou evidenciado na pesquisa foi o imediatismo dos entrevistados quando se põem a resolver problemas. Para responderem ao questionário foi disponibilizado um tempo de 1:30 (uma e meia) horas em uma sala de aula. Foi observado que a grande maioria concluiu 
suas respostas em torno de 55 (cinqüenta e cinco) minutos.

\section{CONCLUSÃO}

Consideramos que os objetivos da pesquisa foram atingidos, pois o questionário aplicado possibilitou perceber o tipo de conhecimento explicitado pelos participantes da pesquisa na elaboração de seus conceitos. Também mostrou o nível de conhecimentos dos participantes nas questões objetivas formuladas em relação aos conteúdos que envolvem o voleibol, enquanto área de conhecimento esportivo.

Contudo, a nossa hipótese inicial não foi plenamente contemplada, pois se esperava que uma quantidade relativamente expressiva de conceitos pudesse ser entendida como sendo científicos nos critérios desta pesquisa. E assim, favorecesse a observação de alguma co-relação entre a organização dos conhecimentos dos alunos em teóricos científicos ou empíricos em relação aos conteúdos do jogo de voleibol com as suas experiências vividas anteriormente nos processos de ensino e aprendizagem dessa modalidade esportiva. De fato ficou evidenciada uma tendência dos alunos a teorizarem de forma empírica a modalidade esportiva voleibol, frequentemente inserida nos currículos escolares e desenvolvida enquanto elemento da cultura corporal e/ ou de movimento.

Por fim, acreditamos que neste contexto de investigação a grande contribuição desta pesquisa tenha sido justamente em função da denotação do tipo de aprendizagem que os estudantes estão encontrando nas instituições de ensino, demarcada especialmente no campo da educação física pelo tratamento corriqueiro, empírico, imediato ou cotidiano dos objetos de aprendizagem, na acepção de Vigotski, Davídov, Libânio, Hedegaard e Ferreira, todos citados neste estudo.

\section{REFERÊNCIAS}

BIZZOCCHI, C. O Voleibol de alio nível da iniciação à competição. São Paulo. Fazendo Arte, 2000.

BOJIKIAN, J. C. M. Ensinando voleibol. São Paulo: Phorte, 2005.

BORSARI, J. R. Voleibol. Aprendizagem e treinamento, um desafio constante. São Paulo: EPU, 1989.

CAPARROZ, E. F. Educação física escolar: política, investigação e intervenção. Vitória: Proteoria, 2001.

CARVALHO, O. M. Voleibol Moderno.

Caderno Técnico - Didárico, o Exercício e a Técnica dos Fundamentos - A Tática de Ataque e Defesa. Ministério da Educação e Cultura. Brasília DF, 1982. CLOES, M., LAPIERRE, A., e PIERON, M. Analyse de situations $d$ 'apprentisage proposées dans un cycled 'enseignement du volley-ball au niveau secondaire. International Volley Tech 4/05.

COLETIVO DE AUTORES. Metodologia do ensino da educação física. São Paulo: Cortez, 1992.

COMTE, A. Curso de filosofia positiva. São Paulo: Nova Cultural, 1988.

CONFEDERAÇÃO BRASILEIRA DE VOLEIBOL. Regras Oficiais de Voleibol. Rio de Janeiro: Sprint, 2013.

CRESWELL, J. W. Projeto de pesquisa: métodos qualitativo, quantitativo e misto / John W. Creswell; tradução Luciana de Oliveira da Rocha. - 2. Ed. - Porto Alegre: Artmed, 2007. 
CUVILLIER, A. Manuel de Philosophie. Tome I. Librairies, Armand Colin. Paris. 1950.

DARIDO, S.C. \& RANGEL, I.C.A. Educação física na escola: implicações para a prática pedagógica. Campos de Rio Claro: Guanabara Koogan, 2005.

DAVIDOV. V. V. O problema da generalização e do conceito na teoria de Vygotsky. Texto de conferência proferida na reunião do Comitê Internacional da International Society for Cultural Research and Activity Theory. Departamento de Ciências Psiquiátricas e Medicina Psicológica da Universidade de Roma. 1992.

DURKHEIM, E. As regras do método sociológico. São Paulo: Editora Nacional, 1985.

FERREIRA, M. M. Desafios e implicações de um ensino com foco no desenvolvimento: a pedagogia de V.V. Davydov. In. LIBÂNEO, J. C.; SUANNO, M. V. R. \& LIMONTA, S. V. (Orgs.) Concepções e práticas de ensino num mundo em mudanças: diferentes olhares para a didática. Goiânia: CEPED/Editora PUC Goiás, 2011.

HARRISON, J. M., PREECE, L. A., BLAKEMORE, C. L., RICHARDS, WILKINSON, C. and FELLINGAM, G.W. Effects of Two Instructional Models-Skill teaching and Mastery Learning-on Skill development, Knowledge, self-Efficacy, and Game Play in Volleyball. ULg, 2010. HEDEGAARD, M. A cultural-historical approach to child development of multiple cultural identities. In: Kontopodis, M.; Wulf, C.\& Fichtner, B. (Eds) Cultural, Historical, Anthropological Perspectives. Series: International perspectives on early childhood education and developmet, Vol. 3, $1^{\text {st }}$ Edition., 2011, VII.

KUNZ, E. Transformação didáticopedagógica do esporte. ljuí: Unijuí. 2000.

LEONTIEV, A. N. Uma contribuição à teoria do desenvolvimento da psique infantil. In: VIGOTSKI, L. S., LURIA, A. R., LEONTIEV, A. N. Linguagem, desenvolvimento e aprendizagem. São Paulo: Ícone, p. 59-83, 1992.

LIBÂNEO, J. C. A didática e a aprendizagem do pensar e do aprender: a teoria histórico-cultural da atividade e a contribuição de V. Davydov. Revista Bras. De Educação, Rio de Janeiro, n.27, p. 5-24, dez. 2004.

. Didática. São Paulo. Cortez Editora, 1990.

MARCHI JÚNIOR, W. Sacando o vôlei / Wanderley Marchi Júnior - São Paulo: Hucitec; ljuí. RS: Unijuí, 2004.

SOLER, R. Educação física inclusiva: em busca de uma escola plural / Reinaldo Soler. - Rio de Janeiro: Sprint, 2005.

. A formação social da mente. Trad. José Cipolla Neto, Luís Silveira Menna Barreto, Solange Castro Afeche. - $7^{\text {a }}$ ed. - São Paulo: Martins Fontes, 2007.

Pensamento e linguagem. Tradução de Jéferson Luiz Camargo, $6^{\mathrm{a}}$ ed. São Paulo: Martins Fontes, 1996. 
V. $26, \mathrm{n}^{\circ} 42$, junho/2014

LEARNING'S VOLLEYBALL AND THE FORMATION OF THE CONCEPT OF THE GAME

\begin{abstract}
This study investigated the knowledge of volleyball developed by 84 students of physical education acquired in earlier phases of the course discipline Volleyball graduation. The objective was to demonstrate the possible relationship between the type of training interventions and the expression of scientific or empirical theoretical knowledge. We used the comparative method in durkheimeana sociological explanation. Was considered thought and empirical concepts the 84 responses to the question about the concept of volleyball. It was concluded that student learning was marked by everyday, empirical, immediate treatment or routine of learning objects within the meaning of Vygotsky, Davydov, Libâneo and others.
\end{abstract}

Key-words: Concept formation; Volleyball; Academic Physical Education.

Recebido em: março/2014

Aprovado em: maio/2014 